Prim. dr sci Zor an Iv a nov, specijalista za medicinu rada Udruženja sudskih veštaka „Vojvodina”, Novi Sad

Prim. dr Ves el in Govedarica, specijalista za medicinu rada Udruženja sudskih veštaka u medicini rada

\title{
PROCENA UMANJENJA ŽIVOTNE AKTIVNOSTI KAO POSLEDICA TRZAJNE POVREDE VRATNE KIČME*
}

\section{UVOD}

Usled razvoja saobraćaja povećana je incidencija trzajne povrede vratne kičme čije posledice mogu imati reperkusije na životnu aktivnost, kao i na obavljanje svake delatnosti, iz čega proizilazi i njen epidemiološki, stručni, sudsko-medicinski, ekonomski i naročito preventivni značaj.

Šteta po osnovu umanjene životne aktivnosti nastaje zbog duševnih bolova koje oštećeni trpi usled nemogućnosti da adekvatno podmiri osnovne životne potrebe (ustajanje iz kreveta, presvlačenje, kretanje, priprema i uzimanje hrane, govorna komunikacija, kontrolisano vršenje nužde, održavanje lične higijene, seksualna aktivnost i dr.), kao i umanjenja životnih aktivnosti koje su za oštećenog imale neku moralnu, neimovinsku vrednost (bavljenje sportom ili hobijem koji je donosio ugled, popularnost i sl.).

Zakon o obligacionim odnosima, u delu koji uređuje naknadu nematerijalne štete, navodi da će za pretrpljene duševne bolove zbog umanjenja životne aktivnosti (izostavlja se „opšte”, jer nije u aktuelnoj pravnoj terminologiji) sud, ako nađe da okolnosti slučaja to opravdavaju, dosuditi pravičnu novčanu naknadu. U skladu s tim, poremećaji organizma koji su doveli do nastanka umanjenja životne aktivnosti, sami po sebi, još uvek ne daju pravo oštećenom

\footnotetext{
*Rad primljen: 21. 02. 2011.
} 
na naknadu štete po ovom osnovu. Potrebno je, naime, da oštećeni zbog umanjenja životne aktivnosti trpi duševne bolove znatnijeg intenziteta.

Za sudskomedicinsko veštačenje od naročite važnosti su one životne aktivnosti zbog čijeg ograničavanja ili onemogućavanja oštećeni trpi duševne bolove znatnijeg intenziteta. To su, pre svega, radnje vezane za zadovoljenje osnovnih životnih potreba, kao i naviknute životne radnje koje pričinjavaju radost i užitak. Upravo se na njima bazira suština sudskomedicinskog veštačenja pretrpljenih i budućih duševnih bolova, zbog čega se, tokom veštačenja, posebno elaboriraju.

Izvori duševnih bolova za ovaj oblik nematerijalne štete, u najopštijim crtama, jesu: umanjena sposobnost ili nesposobnost za obavljanje osnovnih životnih radnji, gubitak ili umanjenje životne radosti, pojačani napori da se ostvari kvalitet života, umanjenje ili gubitak mogućnosti za dalji razvoj ili napredovanje itd., a sve u vezi sa povredom vratne kičme i sledstvenim oštećenjem telesnih funkcija.

Pretrpljeni i budući duševni bolovi zbog umanjene životne aktivnosti procenjuju se $u$ odnosu na intenzitet $u$ kome se objektivno procenjeni poremećaj odražava na životnu aktivnost oštećenog (orijentacioni procenat umanjene ukupne životne aktivnosti), kao i u odnosu na subjektivne, individualne okolnosti koje karakterišu ,životni stil” („life style”) oštećenog. Pritom, od odlučujućeg značaja je stepen duševnih bolova koje je oštećeni pretrpeo i koje će, kod trajnog umanjenja životne aktivnosti i u budućnosti morati da podnosi.

Radi ukupnog sagledavanja štete, po ovom osnovu, potrebno je nabrojati konkretne životne aktivnosti koje oštećeni ne može ostvariti, kao i one koje može ostvarivati samo uz povećane napore ili pod posebnim uslovima. Takođe treba detaljno navesti psihičke tegobe (duševne bolove) koje oštećeni pritom trpi.

Često dolazi do diskrepance između rezultata objektivnih pretraga $i$ jačine subjektivnog stanja povređenog. Iako su s kliničkog aspekta neke tegobe potpuno jasne, one se još ne mogu dostupnom medicinskom dijagnostikom dokučiti.

\subsection{Povreda vratne kičme - definicija i klinička slika}

Povreda vratne kičme nastaje akceleracijsko-deceleracijskim mehanizmom, obično od udara vozila pozadi na drugo vozilo (hiperekstenzione povrede) i kod frontalnog udara (fleksione povrede), kao i kod bočnih sudara (rotacione povrde) kada dolazi do povreda mekih i koštanih struktura vrata ${ }^{1}$. Kod ovog fenomena dolazi do promene brzine (delta v) koja predstavlja razliku brzine pre i posle sudara.

${ }^{1}$ Bradić, V., Jakopec, R., Sitar-Srebočan, V.: Trzajna povreda vratne kralježnice problem medicine, sudstva i osiguratelja, u: Multidisciplinarni aspekti povrede vratne kralježnice, Zagreb, 2002, 33-46. 
Ako je vozilo mirovalo, neko drugo vozilo ga je udarilo i vozilo se nakon sudara kretalo, npr. $17 \mathrm{~km} / \mathrm{h}$, onda delta $\mathrm{v}$ iznosi $0-17=17 \mathrm{~km} / \mathrm{h}$.

Ako se jedno vozilo kretalo brzinom od $100 \mathrm{~km} / \mathrm{h}$, a drugo ga je stiglo i naletelo na njega, pa se ovo prvo kretalo brzinom od npr. $117 \mathrm{~km} / \mathrm{h}$ (usled naleta), onda je i u ovom slučaju promena brzine takođe $17 \mathrm{~km} / \mathrm{h}$.

Ako se grupišu simptomi onda klinička slika podrazumeva:

1. bol kao rezultat oštećenja vratne kičme;

2. druge znake koji se mogu dovesti u vezu sa povredom, ali nisu povezani sa povredom CNS;

3. simptome iritacije produžene moždine i moždanog stabla;

4. verifikovana oštećenja kičmene moždine i motornih i senzitivnih korenova;

5. promenu osnovnog raspoloženja i životnih dinamizama.

Porast incidencije trzajne povrede vratne kičme uslovio je redukciju dijagnostičkog algoritma koji se fokusirao na kliničku sliku i one povređene kojima je najneophodnija i najbrža. To je pre 15 godina bio osnovni motiv za izradu Quebec Task Force (QTF) protokola².

Povrede do kojih dolazi usled trzajne povrede vrata mogu se sistematizovati (Teasell, McCain) kao:

- istegnuće ili ruptura prednjeg longitudinalnog ligamenta*;

- istegnuće ili ruptura zadnjeg longitudinalnog ligamenta*;

- istegnuće ili ruptura interspinoznog ligamenta;

- hernija intervertebralnog diskusa;

- prelom trnastog nastavka pršljena;

- istegnuće ili ruptura mišića vrata*;

- istegnuće ili ruptura zigapofizealnog zgloba;

- potres mozga;

- sindrom gornje torakalne aperture;

- disfunkcija temporomandibularnog zgloba;

- retrofaringealni hematom;

- krvavljenja u zidu jednjaka*;

- krvavljenja u zidu faringsa*;

- povrede cervikalnog simpatikusa;

- ishemija područja irigacije vertebralnim arterijama.

Imajući navedeno u vidu mišljenja smo da je ispravnije govoriti o ,trzajnoj povredi vrata" nego o trzajnoj povredi vratne kičme, jer su trzajnoj povredi izložene sve strukture koje topografski pripadaju vratu (sa dominantnim udelom povređivanja koštanih, zglobnih (veze) i hrskavičnih (discus) delova vratne kičme).

${ }^{2}$ Kejla, Z.: Trzajna povreda vrata - očekivanja, projekcije, realiteti, u: Multikauzalni pristupi u trzajnoj povredi vratne kralježnice, Zagreb, 2002, 57-74.

* Češce se javlja prilikom nesreća. 


\section{CILJ RADA}

Cilj rada je prikaz modela za procenu umanjenja životne aktivnosti oštećenog na osnovu promene brzine (delta v), njegove prethodne životne aktivnosti, trajnih posledica nakon trzajne povrede vratne kičme i individualnih karakteristika.

\section{OCENA UMANJENJA ŽIVOTNE AKTIVNOSTI}

Prva okolnost koju veštak treba da razreši jeste da li je oštećeno lice uopšte pretrpelo telesnu povredu. U slučaju pozitivnog nalaza, neophodno je da se utvrdi vrsta, težina i način povrede ili povreda, način lečenja, vreme završetka lečenja i morfološko-anatomske i funkcionalne posledice povrede. Veštačenje posledica povređivanja ili bolesti obavlja se tek kada je stanje posledica postalo trajno i za predvidivo vreme nepromenljivo.

Za sagledavanje sveukupnih posledica povređivanja vratne kičme potrebno je proceniti, s jedne strane, anatomske i/ili funkcionalne poremećaje, koji se mogu objektivno dokazati i orijentaciono kvantifikovati i, sa druge strane, posledice u psihološkom smislu, koje se manifestuju duševnim bolovima, odnosno patnjom zbog nemogućnosti ili ograničavanja zadovoljavanja osnovnih životnih potreba i uskraćivanja svakidašnjih životnih radosti. Psihološke posledice subjektivne su prirode, individualno zavisne i za njih ne postoji pouzdan pokazatelj. ${ }^{3}$

Umanjenje životne aktivnosti u dostupnoj literaturi se kreće od 10 do $15 \%$ u zavisnosti od toga da li se radi o lakoj ili teškoj telesnoj povredi, o poziciji povređenoga, o mehanizmu povređivanja, jačini i vremenu dejstva sile, o neurološkim oštećenjima hroničnog tipa kompresivne neuropatije, o drugim hroničnim bolestima, zatim o udruženosti povreda glave (kontakt čelo-staklo), grudnog koša (volan-grudna kost), ključna kost (pojas), o politraumi.

Za priznavanje trzajne povrede vrata (WI- wiplash injury) mora postojati jasan razvoj tegoba u vezi sa povredom i akcidentom koji ukazuje na uzročno-posledičnu vezu.

${ }^{3}$ Banic, B., Petersen-Felix, S., Andersen, O., Radanov, B., Villiger, P., Arendt-Nielsen, L., Curatolo, M.: Evidence for spinal cord hypersensitivity in chronic pain after whiplash injury and in fibromyalgia, Pain 2004, 107:7-15.

Elliott, J., Jull, G., Noteboom, T., Darnell, R.; Galloway, G, Gibbon, W.: Fatty infiltration in the cervical extensor muscles inpersistent whiplash associated disorders: an MRI analysis, Spine 2006, 31:E847-51.

Haldeman, S., Carroll, L., Cassidy, D.; Schubert, J.; Nygren, A.: The Bone and Joint Decade 2000-2010. Task Force on Neck Pain and Its Associated Disorders executive summary, Spine 2008, 33:S5-S7. 
Pri utvrđivanju umanjenja životne aktivnosti moraju se navesti sve posledice radi kojih je smanjenje (normalne, uobičajene) aktivnosti povređenog ograničeno, otežano ili onemogućeno delimično ili u celosti. ${ }^{4}$

Samo morfološki supstrat nakon povrede vratne kičme sa posledicama na obavljanje životne aktivnosti predstavlja osnovu za ozbiljno cenjenje umanjenja životne aktivnosti i radne sposobnosti.

Utvrđivanje zdravstvenog stanja pre povrede, analiza dostupnih medicinskih nalaza nakon povrede, ustanovljavanje definitivnog stanja, osnov su za ocenu životne aktivnosti. Nakon saobraćajne nezgode javlja se ,psihička nadgradnja" učesnika u saobraćajnoj nezgodi sa psihičkim tendencijama i subjektivnim simptomima koji mogu biti u diskrepanci sa morfološkim supstratom iz medicinske dijagnostike i kliničkog nalaza.

Telesna povreda sama po sebi nije osnov za naknadu preko umanjenja životne aktivnosti, već su to isključivo duševni bolovi koje oštećeni trpi zato što, zbog posledica zadobijene povrede vratne kičme, ne može da obavlja ili otežano obavlja naviknute životne radnje. Bitno je ustanoviti ,privremene posledice” $\mathrm{i}$,trajne posledice" i utvrditi vreme kada prve prestaju ili se pretvaraju u druge ${ }^{5}$, odnosno da li se radi o privremenom ili trajnom umanjenju životne aktivnosti.

Kasni wiplash sindrom javlja se u 15 do $25 \%$ osoba koje su pretrpele ovu povredu. ${ }^{6}$

Za ozbiljno shvatanje ovog sindroma neophodno je da su tegobe verifikovane nakon godinu dana provedenog lečenja i rehabilitacije. Okolnosti pri nastanku trzajne povrede vrata (individualna osetljivost osobe, položaj glave prilikom udesa, eventualni bolni lumbalni sindrom, brzina vozila, smer prilikom udara, konstrukcija kabine, sedišta, naslona i drugo) utiču na posledice. Ukoliko su okolnosti nepovoljnije, posledice su izraženije i znatnije utiču na ocenu opšte životne aktivnosti nakon povređivanja, odnosno intenzitet i trajanje fizičkih bolova i duševnih patnji.

Lekar se ne sme ogrešiti o tegobe povređenog, on leči i mora imati poverenje pacijenta i mora voditi ozbiljnu brigu o njemu, registrovati sve njegove tegobe (glavobolju, vrtoglavicu, nauzeju, trnjenje u rukama, smetnje vida, neurološke tegobe, psihička stanja, stres zbog povrede i dr.).

${ }^{4}$ Mihalić, A., Burnać, J.: Osvrt na veštačenja posledica trzajne povrede vrata, u: Multikauzalni pristupi u trzajnoj povredi vratne kralježnice, Zagreb, 2002, 217-221.

${ }^{5}$ Vrabl, M.: Problemi ocjenjivanja trajnih posledica trzajne povrede vratne kičme u odštetnim zahtevima, u: Multikauzalni pristupi u trzajnoj povredi vratne kralježnice, Zagreb, 2002, 157-67.

${ }^{6}$ Kamper, S., Rebbeck, T., Maher, C., McAuley, J., Sterling, M.: Course and prognostic factors of whiplash: a systematic reviewand meta-analysis, Pain, 2008, 138:617-29.

Rebbeck, T., Sindhausen, D., Cameron, I.: A prospective cohort study of health outcomes following whiplash associated disorders in an Australian population, Injury Prevention, 2006, 12:86-93. 


\subsection{Prikaz modela}

Posmatrane su naviknute životne radnje neophodne svakom čoveku kao $\mathrm{i}$ individualne radnje pojedinca koje nisu uobičajene, radi dobijanja utiska o obimu umanjenja životne aktivnosti.

Prema ovom modelu prvih osam segmenata životnih aktivnosti spadaju u naviknute životne aktivnosti vezane za svakodnevni život (osoba mora svakodnevno da se samostalno oblači, samostalno hrani i samozbrinjava, kao i da održava uobičajene kontakte sa okolinom).

Da li osoba može podizati kvalitet svoga života (,nadgradnja”) obavljanjem neuobičajenih životnih aktivnosti kao što su individualna ili grupna sportska aktivnost, rekreacija, ekstremne aktivnosti kao što su borilački sportovi, planinarenje, ekstremni sportovi, ronjenje, vazduhoplovstvo, maraton, hobi i druge aktivnosti koje donose ugled i popularnost... ustanoviće se u svakom individualnom slučaju i adekvatno ceniti. Nadgradnju neuobičajenih životnih aktivnosti treba posmatrati u odnosu na dužinu vremenskog perioda njihovog upražnjavanja, kao i u odnosu na starosnu dob. Ukoliko se osoba, na primer, bavila ekstremnim sportom, do svoje 38 godine starosti, a povređena je u 61 . godini starosti kada se više ne bavi ekstremnom aktivnošću, nije ispravno da se njena životna aktivnost ceni u odnosu na aktuelno umanjenje životne aktivnosti. Ako se bavi nadgradnjom životnih aktivnosti, onda je korektno da se ceni delimična ili trajna nesposobnost za obavljenje ovih aktivnosti, ali opet do razumne granice godina starosti kada, zbog umanjenja fizioloških kapaciteta praktično nije u stanju da se bavi ovom delatnošću usled krivnje štetnika.

U oceni umanjenja životne aktivnosti bitno je ustanoviti prethodnu životnu aktivnost lica koje je pretpelo povredu vratnog dela kičme. Osoba je mogla biti uobičajeno aktivna, natprosečno ili veoma životno aktivna.

Radi cenjenja prethodne životne aktivnosti neophodno je posmatrati navedene dve vrste aktivnosti.

Jedna aktivnost odnosi se na obavljanje uobičajenih svakodnevnih aktivnosti i potreba kao što su kognitivne funkcije, psihička kontrola, samozbrinjavanje, motilitet, samostalno konzumiranje jela i pića, uredan san, obuvanje, oblačenje, higijena tela, održavanje stana, povremena rekreacija.

Druga aktivnost vezana je za nadgradnju, odnosno neuobičajene aktivnosti koje ne mora i ne može da obavlja svako lice nego je to individualni izbor, stvar njegove sposobnosti, povišenog kapaciteta životnih radnji usmerenih ka podizanju kvaliteta sopstvenog života. Ove aktivnosti čine osobi ličnu životnu radost i sreću.

Navedene aktivnosti mogu biti povremene i trajne, mogu biti individualne ili grupne, mogu biti lakše ili teže. Treba voditi računa u oceni da su ove aktivnosti, koje podižu kvalitet življenja, više vrednovane ako se ostvaruju u 
socijalnom miljeu, odnosno uz prisustvo drugih poznatih osoba sa kojima se doživljava potpuniji socijalni kontakt od uticaja na životnu radost i sreću svake osobe (Tabela 1).

Utvrđivanjem zdravstvenih posledica koje su trajnog karaktera, određuje se da li je došlo nakon povređivanja i sprovedene rehabilitacije do manjeg ili većeg narušavanja funkcionalnosti segmenata svih životnih aktivnosti po ovom modelu, odnosno umanjenja životne aktivnosti kao posledica trzajne povrede vratne kičme. ${ }^{7}$

Tabela 1

\begin{tabular}{|c|c|c|}
\hline Segmenti životne aktivnosti & maksimalno & nađeno \\
\hline 1. Kognitivne funkcije, psihička kontrola & 10 & \\
\hline 2. Samozbrinjavanje & 10 & \\
\hline 3. Motilitet & 10 & \\
\hline 4. Samostalno konzumiranje jela i pića & 10 & \\
\hline 5. Uredan san & 10 & \\
\hline 6. Obuvanje, oblačenje, higijena tela, održavanje stana & 10 & \\
\hline $\begin{array}{l}\text { 7. Obrazovanje (odlaganje, otežano, nemogućnost), soci- } \\
\text { jalizacija (druženje, bioskop, pozorište, restoran, crkva) } \\
\text { porodični odnosi (supružnik, deca, ostala familija) }\end{array}$ & 10 & \\
\hline $\begin{array}{l}\text { 8. Aktivnosti povremene (sportska rekreacija, individual- } \\
\text { na, grupna...) }\end{array}$ & 10 & \\
\hline $\begin{array}{l}\text { 9. Aktivnosti redovne (sportska rekreacija, individalne, } \\
\text { lakše grupne: fudbal, odbojka, tenis...) }\end{array}$ & 10 & \\
\hline $\begin{array}{l}\text { 10. Aktivnosti ekstremne (sportske borilački sportovi, } \\
\text { planinarenje, ekstremni sportovi, ronjenje, vazduho- } \\
\text { plovstvo, maraton...) }\end{array}$ & 10 & \\
\hline Svega & 100 & \\
\hline$\%$ & 100 & \\
\hline
\end{tabular}

Ocena prethodne životne aktivnosti

Sposobnost za obavljenje svake radnje donosi $10 \%$. Sumarna ocena se dobija na kraju zbrajanjem vrednosti svakog segmenta. Stepen umanjenja

${ }^{7}$ Sterling, M., Jull, G., Vicenzino, B., Kenardy, J., Darnell, R.: Physical and psychological factors predict outcome following whiplash injury, Pain, 2005, 114:141-8. 
aktuelne životne aktivnosti utvrđuje se na osnovu opservacije, validnog upoznavanja sa prethodnim životnim aktivnostima, kliničkog pregleda i medicinske dokumentacije.

\section{Mogućnost realizacije segmenata životne aktivnosti}

I zadovoljavajuće funkcije ............9-10 bodova

II blaži nedostatak funkcije .......... 7-8 bodova

III umereni nedostatak funkcije . . . . . . . . 5-6 bodova

IV značajan nedostatak funkcije. ......... 3-4 boda

V ekstremni nedostatak funkcije . ....... 0-2 boda

Dobijeni rezultat na osnovu kriterijuma ukazuje da li je osoba uobičajeno aktivna, da li obavlja sve neophodne životne radnje, da li se osoba koja je natprosečno aktivna bavi nekom aktivnošću iz ličnog zadovoljstva, ili je veoma aktivna ličnost koja se bavi težim aktivnostima, odnosno ekstremnom aktivnošću radi ličnog zadovoljstva.

Tabela 2

\begin{tabular}{|l|l|}
\hline Do $50 \%$ & Uobičajeno aktivan \\
\hline $50 \%$ do $70 \%$ & Natprosečno aktivan \\
\hline Preko $70 \%$ & Veoma aktivan \\
\hline
\end{tabular}

Kriterijumi za ocenu prethodne životne aktivnosti

\subsection{Ocena umanjenja životne aktivnosti nakon trzajne povrede vratne kičme}

$\mathrm{Na}$ osnovu težine trajnih posledica i prethodne životne aktivnosti kvantifikovano je umanjenje aktuelne životne aktivnosti oštećenog.

Model se oslanja inicijalno na početne vrednosti QTF protokola, a uvažava definitivnu ocenu posledica baziranu na dijagnostici i kliničkoj funkcionalnosti organskih sistema.

Prema QTF protokolu aktuelni simptomi trzajne povrede vrata počinju od nultog stepena, kada praktično nema nikakvih posledica nakon povrede, te prema tome, nakon provedenog medicinskog tretmana nema ni stvarnih osnova za umanjenje životne aktivnosti usled trajnih posledica. Lečenje obično traje do tri meseca nakon povrede. Preporuka je lečenje, mirovanje i psihološka podrška. Međutim, praksa ukazuje da se trajne posledice mogu očekivati i pri brzini do $11 \mathrm{~km} / \mathrm{h}$. Ako se jave, one se utvrđuju kao posledice u višim stepenima po QTF 
protokolu, ceni se prethodna životna aktivnost. Umanjenje životne aktivnosti usled trajnih posledica iskazuje se u odgovarajućem stepenu QTF protokola.

Prvi stepen prema QTF protokolu dijagnostikuje se ukočenošću i bolnim vratom, nema kliničkih znakova povrede, nema spazma paravertebralne muskulature. Očekivati je da je ovakvo stanje prolazno i može se govoriti o privremenom (vremenski ograničenom) umanjenju životne aktivnosti koje traje do povlačenja subjektivnih simptoma povređenog. Lečenje traje od tri meseca do jedne godine nakon povrede. Preporuka je fizikalni tretman i psihološka podrška. Slično prethodno rečenom, trajne posledice mogu se očekivati i pri brzini od 11 do $15 \mathrm{~km} / \mathrm{h}$. U tom slučaju se utvrđuju kao posledice u višim stepenima prema QTF protokolu uz ocenu prethodne životne aktivnosti. Umanjenje životne aktivnosti iskazuje se u odgovarajućem stepenu QTF protokola.

Drugi stepen dijagnostikuje se ukočenošću i/ili bolnim vratom i spazmom paravertebtalne muskulature, povređenom pravi smetnje pri obavljanju svakodnevnih životnih aktivnosti. Ove posledice su trajne i u zavisnosti od obima prethodne životne aktivnosti osobe ,vuku” umanjenje životne aktivnosti od 1\% do 3\%. Dakle, osoba je sa funkcionalnim smetnjama 12 meseci nakon povrede, javljaju se bolovi pri maksimalnoj amplitudi vratne kičme, pri savladavanju fizičkog otpora, što je od uticaja na obavljanje životnih radnji.

Kod trećeg stepena, sem već ukočenog i/ili bolnog vrata, postoje znaci neurološkog oštećenja, koje se može i mora objektivizovati. Posledice su trajne i u odnosu na prethodne aktivnosti osobe dovode do umanjenja opšte životne aktivnosti od $4 \%$ do $6 \%$. Dakle, osoba je sa funkcionalnim smetnjama, sa verifikovanim neurološkim posledicama, javljaju se intenzivni bolovi pri uobičajenim pokretima vratne kičme, pri savladavanju fizičkog otpora što je od većeg uticaja na obavljenje svakodnevnih životnih radnji i aktivnosti vezanih za „nadgradnju”opštih životnih aktivnosti 12 meseci nakon povrede.

Kod četvrtog stepena postoje radiološki verifikovan supstrat i klinički instabilitet. Posledice su trajne i u odnosu na prethodne aktivnosti osobe dovode do umanjenja opšte životne aktivnosti od 7\% do 9\%. Javljaju se bolovi koji značajno umanjuju obavljanje svakodnevnih životnih radnji i aktivnosti vezanih za uobičajene životne potrebe i ,nadgradnju” životnih aktivnosti. Ostavljen je prostor i za veće umanjenje životne aktivnosti u zavisnosti od težine kliničke slike i prethodne životne aktivnosti povređenog, obično 12 meseci nakon povrede. Uvidom u literarne navode predstavljena je gruba analogija promene brzine (delta v), stepeni QTF protokola, trajnih posledica (WAD) i predloga za umanjenje životne aktivnosti u odnosu na njihov prethodni kvalitet. Ova analogija nije isključiva (teže povređivanje može nastati i pri manjim brzinama i obratno) i usmerena je na olakšanje rada i evaluaciju celog procesa od nastanka, preko medicinskog tretmana, uvida u prethodnu životnu aktivnost povređenog i trajnih posledica nakon povređivanja (Tabela 3 ). 
Tabela 3

\begin{tabular}{|c|c|c|c|c|}
\hline Delta v & $\begin{array}{l}\text { Stepen po } \\
\text { QTF proto- } \\
\text { kolu, Klinički } \\
\text { nalaz }\end{array}$ & $\begin{array}{l}\text { Posledice; } \\
\text { Privremene } \\
\text { Trajne (WAD) }\end{array}$ & $\begin{array}{l}\text { Ocena } \\
\text { prethodne } \\
\text { životne } \\
\text { aktivnosti }\end{array}$ & $\begin{array}{l}\text { Ocena } \\
\text { umanjenja } \\
\text { životne } \\
\text { aktivnosti }\end{array}$ \\
\hline $\begin{array}{l}\text { Ispod } \\
11 \mathrm{~km} / \mathrm{h}\end{array}$ & $\begin{array}{l}\text { 0 } \\
\text { Samo anamne- } \\
\text { stički podatak } \\
\text { o mogućnosti } \\
\text { trzajne povre- } \\
\text { de, bez tegoba, } \\
\text { bez kliničkih } \\
\text { znakova po- } \\
\text { vrede. }\end{array}$ & $\begin{array}{l}\text { Privremene: } \\
\text { vegetativni simp- } \\
\text { tomi, strah, bol, } \\
\text { neizvesnost, } \\
\text { zadovoljavajuće } \\
\text { funkcije. }\end{array}$ & $\begin{array}{l}\text { Ceni se } \\
\text { u slučaju } \\
\text { trajnih } \\
\text { posledica. }\end{array}$ & $\begin{array}{l}\text { Lečenje do } \\
3 \text { meseca, } \\
\text { nakon čega se } \\
\text { utvrđuju trajne } \\
\text { posledice i ceni } \\
\text { umanjenje } \\
\text { (specijalistički } \\
\text { pregled, } \\
\text { psihološka } \\
\text { podrška). }\end{array}$ \\
\hline $\begin{array}{l}\text { Od } \\
11-15 \\
\mathrm{~km} / \mathrm{h}\end{array}$ & $\begin{array}{l}1 \\
\text { Ukočen ili bo- } \\
\text { lan vrat, nema } \\
\text { kliničkih zna- } \\
\text { kova povrede, } \\
\text { nema spazma } \\
\text { paravertebralne } \\
\text { muskulature. }\end{array}$ & $\begin{array}{l}\text { Privremene/trajne: } \\
\text { prolazna multipla } \\
\text { lezija mekih tkiva, } \\
\text { bol pri fleksiji, ek- } \\
\text { stenziji, lateroflek- } \\
\text { siji, cirkumdukciji } \\
\text { vratne kičme, } \\
\text { zadovoljavajuće } \\
\text { funkcije. }\end{array}$ & $\begin{array}{l}\text { Ceni se } \\
\text { u slučaju } \\
\text { trajnih } \\
\text { posledica. }\end{array}$ & $\begin{array}{l}\text { Lečenje od } 3 \\
\text { dol2 meseci, } \\
\text { nakon čega se } \\
\text { utvrđuju trajne } \\
\text { posledice i ceni } \\
\text { umanjenje. } \\
\text { Fizikalni } \\
\text { tretman. } \\
\text { Psihološka } \\
\text { podrška. } \\
\text { Inkorporacija } \\
\text { u radni proces. }\end{array}$ \\
\hline $\begin{array}{l}\text { Od } \\
15-30 \\
\mathrm{~km} / \mathrm{h}\end{array}$ & $\begin{array}{l}2 \\
\text { Ukočen } \\
\text { i/ili bolan vrat, } \\
\text { spazam para- } \\
\text { vertebralne } \\
\text { muskulature. }\end{array}$ & $\begin{array}{l}\text { Trajne: } \\
\text { istegnuće i krvav- } \\
\text { ljenje u mekim tki- } \\
\text { vima, mišići, } \\
\text { ligamenti, kapsule, } \\
\text { tetive, jednjak, } \\
\text { grkljan, ograničenje } \\
\text { fiziološke amplitude } \\
\text { vratne kičme za 1/4 } \\
\text { u najmanje jednoj } \\
\text { kretnji, blaži nedo- } \\
\text { statak funkcije. }\end{array}$ & $\begin{array}{l} \\
\\
\\
\text { - uobičajeno } \\
\text { aktivan } \\
\text { - natproseč- } \\
\text { no aktivan } \\
\text { - veoma } \\
\text { aktivan }\end{array}$ & $\begin{array}{l}\text { Nakon lečenja } \\
\text { od } 12 \text { meseci se } \\
\text { utvrđuju trajne } \\
\text { posledice i ceni } \\
\text { umanjenje: } \\
1 \% \\
2 \% \\
3 \%\end{array}$ \\
\hline
\end{tabular}




\begin{tabular}{|c|c|c|c|c|}
\hline $\begin{array}{l}\text { Preko } \\
30 \mathrm{~km} / \mathrm{h}\end{array}$ & $\begin{array}{l}3 \\
\text { Ukočen i/ili } \\
\text { bolan vrat, zna- } \\
\text { ci neurološkog } \\
\text { oštećenja. }\end{array}$ & $\begin{array}{l}\text { Trajne: } \\
\text { lezija nerava, sla- } \\
\text { bost muskulature } \\
\text { gornjih ekstremite- } \\
\text { ta, ograničenje am- } \\
\text { plitude vratne ki- } \\
\text { čme za } 1 / 3 \text { fiziolo- } \\
\text { ške u najmanje jed- } \\
\text { noj kretnji, } \\
\text { umereni nedostatak } \\
\text { funkcije. }\end{array}$ & $\begin{array}{l} \\
\\
\text { - uobičajeno } \\
\text { aktivan } \\
\text { - natproseč- } \\
\text { no aktivan } \\
\text { - veoma } \\
\text { aktivan }\end{array}$ & $\begin{array}{l}\text { Nakon lečenja } \\
\text { od } 12 \text { meseci se } \\
\text { utvrđuju trajne } \\
\text { posledice i ceni } \\
\text { umanjenje: } \\
4 \% \\
5 \% \\
6 \%\end{array}$ \\
\hline $\begin{array}{l}\text { Preko } \\
40 \mathrm{~km} / \mathrm{h}\end{array}$ & $\begin{array}{l}4 \\
\text { Ukočen i/ili } \\
\text { bolan vrat, } \\
\text { RTG verifiko- } \\
\text { van instabilitet } \\
\text { ili prelom. }\end{array}$ & $\begin{array}{l}\text { Trajne: } \\
\text { kompromitovan sta- } \\
\text { bilitet, verifikovana } \\
\text { radiološka lezija, } \\
\text { ograničenje ampli- } \\
\text { tude vratne kičme } \\
\text { za } 1 / 2 \text { fiziološke, } \\
\text { slabost muskulature } \\
\text { gornjih ekstremite- } \\
\text { ta, u najmanje jed- } \\
\text { noj kretnji, značajan } \\
\text { nedostatak funkcije. }\end{array}$ & $\begin{array}{l} \\
\\
\text { - uobičajeno } \\
\text { aktivan } \\
\text { - natproseč- } \\
\text { no aktivan } \\
\text { - veoma } \\
\text { aktivan }\end{array}$ & $\begin{array}{l}\text { Nakon lečenja } \\
\text { od } 12 \text { meseci se } \\
\text { utvrđuju trajne } \\
\text { posledice i ceni } \\
\text { umanjenje: } \\
7 \% \\
8 \% \\
9 \% \text { i više. }\end{array}$ \\
\hline
\end{tabular}

Promena brzine (delta v), QTF protokol, privremene i trajne zdravstvene posledice, prethodna životna aktivnost, ocena umanjenja životne aktivnosti.

Pri proceni umanjenja životne aktivnosti razmatra se i individualnost oštećenog. U tom smislu postoje predlozi da se u odnosu na ovu okolnost dodaje do 3\% na osnovnu ocenu i to za: dob (do 45. godine starosti), pol (ženski), ranija deklanširajuća oboljenja i povrede vratne regije, kao i za specifičnost prirode oštećenog.

Posledice trzajne povrede vratne kičme mogu biti privremene kada se preporučuje lečenje od 6 do najviše 12 meseci.

Trajne posledice se manifestuju posle obavljenog lečenja i ostaju nakon 12 meseci trajno (Wiplash associated disorder - WAD).

Zadatak lekara sudskog veštaka jeste da sa medicinskog aspekta kvantifikuje, tj. odredi obim poremećaja organizma nastalog isključivo kao posledica aktuelnog povređivanja zbog kojih su uobičajene životne aktivnosti oštećenog onemogućene, ograničene ili otežane. Zatim, da proceni uticaj poremećaja na sposobnost oštećenog za obavljanje svakodnevnih, uobičajenih životnih aktivnosti i razmatra duševne bolove koje oštećeni s tim u vezi trpi. 
Treba imati u vidu da umanjena životna aktivnost obuhvata sva ograničenja u životnim aktivnostima oštećenog koje je ostvario, ili bi ih po redovnom toku stvari u budućnosti izvesno ostvarivao. Pod ograničenjem se podrazumeva i vršenje aktivnosti uz povećane napore ili pod posebnim uslovima. Veštaci imaju ulogu da utvrde sve posledice zbog kojih se normalna aktivnost oštećenog ograničava ili će biti otežana. Zato u nalazu i mišljenju predloženi procenat umanjenja životne aktivnosti predstavlja osnovu na koju se nadgrađuje individualnost oštećenog.

Složenost veštačenja umanjene životne aktivnosti zapravo i proizilazi iz činjenice da se posledice povređivanja vratne kičme individualno procenjuju u odnosu na raniju životnu aktivnost i psihofizičke karakteristike oštećenog.

Za sudskomedicinsko veštačenje od naročite važnosti su one životne aktivnosti zbog čijeg ograničavanja ili onemogućavanja oštećeni trpi duševne bolove znatnijeg intenziteta. To su, pre svega, radnje vezane za zadovoljenje osnovnih životnih potreba, kao i naviknute životne radnje koje pričinjavaju radost i užitak. Upravo se na njima bazira suština sudskomedicinskog veštačenja pretrpljenih i budućih duševnih bolova, zbog čega se, tokom veštačenja, posebno elaboriraju.

Sa vrednošću umanjenja životne aktivnosti može se uporediti visina materijalne štete i za očekivati je pozitivna linearna korelacija, što takođe može biti fakultativni parametar u proceni umanjenja životne aktivnosti.

Treba utvrditi što objektivnija merila, kako bi se kriterijumi u praksi izjednačili i kako bi sud na osnovu objektivnih pokazatelja i subjektivnih okolnosti oštećenom dosudio pravičnu naknadu. Zato veštak treba precizno da opiše u čemu se sve sastoji umanjena životna aktivnost, koja su sve ograničenja koja trpi oštećeni (neophodnost ulaganja posebnih fizičkih napora, povećane potrebe, mogućnost bavljenja slobodnim aktivnostima, suženje izbora buduće profesije itd.). Veštak treba da naznači koje životne aktivnosti oštećeni ne može ostvarivati, a koje može samo uz povećane napore, te da objasni ozbiljnost, jačinu i trajanje posledica - da li se radi o privremenim ili trajnim posledicama. ${ }^{8}$

\section{ZAKLJUČCI}

1. Umanjenje životne aktivnosti nastaje usled trajnih posledica trzajne povrede vratne kičme (Wiplash associated disorder - WAD).

\footnotetext{
${ }^{8}$ Govedarica, V., Filipović, D., Vidaković, A.: Preporuke za veštačenje umanjenja životne aktivnosti. Udruženje sudskih veštaka u medicini rada, Beograd, 2010.
} 
2. Umanjenje životne aktivnosti nakon trzajne povrede vratne kičme individualno se procenjuje u odnosu na objektivne posledice predmetnog povređivanja, kao i u odnosu na prethodnu životnu aktivnost i psihofizičke karakteristike oštećenog (starost, pol, deklanširajuće bolesti i povrede). Takođe se razmatraju biomehanički podaci, rezultati dijagnostike, efekti sprovedenog lečenja i rehabilitacije.

3. Kvalitet ocene umanjenja opšte životne aktivnosti nakon trzajne povrede vratne kičme zavisi od rezultata rada i nalaza svih stručnih profila koji su uključeni u lečenje i rehabilitaciju oštećenog, kao i ažuriranja dokumentacije koja se upoređuje u slučaju pogoršanja stanja (reevaluacija) i ukazuje na potrebu multidisciplinarnog pristupa.

4. Trzajnoj povredi ovog dela tela su izložene sve strukture koje topografski pripadaju vratu (sa dominantnim udelom povređivanja koštanih, zglobnih i hrskavičnih delova vratne kičme), zbog čega je ispravnije govoriti o „trzajnoj povredi vrata" nego o „trzajnoj povredi vratne kičme". 